\title{
The assessment of phonatory and ventilatory functions in patients after microsurgery for Reinke's edema
}

\author{
Katarzyna Ura-Sabatt, ${ }^{1, A-D}$, Joanna Morawska ${ }^{2, C, D}$, Wojciech Domka ${ }^{1, C, D}$, \\ Marta Gamrot-Wrzoł ${ }^{3, C, D}$, Wojciech Scierski ${ }^{3, A, E}$, Ewa Niebudek-Bogusz ${ }^{2, A, F}$ \\ ${ }^{1}$ Clinical Department of Otorhinolaryngology, Frederic Chopin Clinical Voivodeship Hospital No. 1, Rzeszów, Poland \\ 2 Nofer Institute of Occupational Medicine, Department of Audiology and Phoniatrics, Łódź, Poland \\ ${ }^{3}$ Department of Otorhinolaryngology and Laryngological Oncology in Zabrze, Medical University of Silesia, Katowice, Poland \\ A - research concept and design; B - collection and/or assembly of data; C - data analysis and interpretation; \\ $D$ - writing the article; $E$ - critical revision of the article; $F$ - final approval of the article
}

Address for correspondence

Katarzyna Ura-Sabat

E-mail: urka23@wp.pl

Funding sources

None declared

Conflict of interest

None declared

Received on May 12, 2019

Reviewed on May 31, 2019

Accepted on January 21, 2020

Published online on July 3,2020

Cite as

Ura-Sabat K, Morawska J, Domka W, Gamrot-Wrzoł M, Scierski W, Niebudek-Bogusz E. The assessment of phonatory and ventilatory functions in patients after microsurgery for Reinke's edema. Adv Clin Exp Med. 2020;29(7):865-871. doi:10.17219/acem/116755

DOI

10.17219/acem/116755

Copyright

Copyright by Author(s)

This is an article distributed under the terms of the

Creative Commons Attribution 3.0 Unported (CC BY 3.0)

(https://creativecommons.org/licenses/by/3.0/)

\begin{abstract}
Background. Short and long-term results of microsurgical treatment with the mini-microflap technique in patients with Reinke's edema (RE) were assessed based on the phonatory and ventilatory functions of the larynx.
\end{abstract}

Objectives. To assess the short and long-term results of microsurgical treatment with the mini-microflap technique in patients with RE based on the phonatory and ventilatory functions of the larynx.

Material and methods. Twenty patients diagnosed with advanced stage of RE confirmed with laryngovideostroboscopy (LVS) were enrolled in the study. Phonatory function disturbances were additionally assessed on the basis of Maximum Phonation Time (MPT) measurement, Voice Handicap Index (VHI) and Voice-Related Quality of Life (V-ROOL) questionnaires. Ventilatory function was assessed using spirometry. The aforementioned complex examinations were conducted prior to surgery and 1,6 and 9 months following the surgery.

Results. Good postsurgical results were obtained in subjective and objective evaluation, which assessed the phonatory function and ventilatory parameters. Post-surgery increase in MPT, VHI and VQROL was noticed in all patients in 3 check points $(p<0.001)$. The results demonstrate postsurgical improvement for some LVS parameters, including assessment of glottis closure $(p<0.003)$ observed 6 months after the surgery. An improvement in most of the ventilation parameters was observed also 6 months after surgery $(p<0.001)$. For the spirometry flow parameter PEF, significant improvement was noted in each check point ( $\mathrm{p} 1<0.004$, p6 $<0.001$, p9 < 0.001). The study revealed a correlation between phonatory parameter - MPT and PEF observed 1 month after the procedure $(p=0.026)$, confirming the interdependence of ventilatory efficiency and phonatory condition of larynx.

Conclusions. Mini-microflap surgery brings satisfactory clinical effect in patients with advanced stages of RE by optimization of phonatory and ventilatory functions of the larynx.

Key words: spirometry, voice quality, long-term outcomes, mini-microflap surgery, Reinke's edema 


\section{Introduction}

Reinke's edema (RE) belongs to a group of benign masses of vocal folds (BVFM) deteriorating both phonatory and ventilatory function of the larynx. ${ }^{1-3}$ Precisely, RE is classified as a disease of the lamina propria, and as its name indicates, superficial lamina propria, also referred to as Reinke's space of the vocal fold layer, is affected by this disorder. ${ }^{4}$ Reinke's edema constitutes about $6-10 \%$ of all non-malignant pathologies within the glottis and is most commonly observed in middle-aged women., 5 Longlasting smoking has been found to be the most important risk factor in the etiopathogenesis of RE. ${ }^{1,7}$ Four clinical stages can be distinguished, depending both on the extent of lesions on vocal folds and on glottis area narrowing caused by swollen folds. ${ }^{8}$ One of the first symptoms of RE are voice disorders, most frequently manifesting themselves as persistent hoarseness and a lower than normal pitch, deteriorating the quality of voice, especially in women. ${ }^{9-11}$ In more advanced stages of RE, due to the narrowing of the glottis area, ventilatory capacity can also be compromised, which is typically observed as gradually aggravating respiratory problems. ${ }^{12}$ In the case of large, bilateral RE, stridor can be noticed, caused by chronic edematous hypertrophy of vocal folds obstructing the glottis, especially its posterior part responsible for the respiratory function of larynx. ${ }^{13}$ Diagnosis of RE is made during a routine laryngological examination, although instrumental evaluation of the larynx by means of laryngovideostroboscopy is a valuable contribution in the diagnostic procedure. ${ }^{14}$

The management depends on the stage of the disease. At the $1^{\text {st }}$ and $2^{\text {nd }}$ clinical stages of RE conservative treatment is usually effective. ${ }^{4}$ Microsurgery is the first treatment of choice at the $3^{\text {rd }}$ and $4^{\text {th }}$ stages because of the potential ventilatory function disorders. The previously used decortication technique (stripping) ${ }^{15,16}$ was unsatisfactory both for the surgeon and the patient because of the poor post-surgery quality of the voice. ${ }^{12,15-17}$ For this reason, the mini-microflap technique has become a more frequently used method in phonosurgical treatment of RE as a technique widening the ventilatory area of glottis and, at the same time, saving the phonatory function of the larynx. ${ }^{18-21}$

When reviewing the available literature, the authors did not find any studies that evaluated the effects of the complex microsurgical treatment of RE, including those that monitored both phonatory and respiratory functions simultaneously. The aim of the study was to comparatively assess the abovementioned functions of the larynx in patients with RE who underwent mini-microflap phonosurgery.

\section{Material and methods}

The prospective study was carried out in 20 patients with advanced RE. The patients were qualified for phonosurgery on the basis of laryngological examination complemented with instrumental examination - laryngovideostroboscopy (LVS). Additionally, the assessment of the phonatory and ventilatory function of the larynx was performed before and after the surgery according to a scheme described below. The examinations after operation were conducted in 3 check points: at short-term (1 month) and long-term periods ( 6 and 9 months after the surgery).

\section{The mini-microflap technique}

The applied surgical mini-microflap technique was intended to both decrease the mass of the vocal folds and broaden the glottis, as well as to maintain layered, functional composition of the vocal fold. All patients underwent laryngeal microsurgery under general anesthesia. The mini-microflap technique was applied in all cases as a one-step procedure. It is based on performing an incision of the upper edge of the vocal fold without affecting its middle part. The surgery was performed with the Kleinsasser set. The Reinke's space was opened along the superior surface of the vocal fold near the ventricle, saving the anterior commissure. Subepithelial layer was dissected to aspirate fluid accumulated in the Reinke's space. The mucous, dense content of Reinke's space was sucked out and the excess mucosa was removed minimally as necessary. The surgical site was covered with a tissue layer to form a strong bond and to hold the tissue in place to facilitate healing. Tissue glue was applied when necessary. ${ }^{2,4,5,7,13}$ All the patients were hospitalized for 1 day after the surgery. The patients were instructed to follow 1 week of complete vocal rest, so as not to traumatize vocal folds and were advised to respect vocal hygiene rules, with particular emphasis put on the absolute necessity of smoking cessation. They were also informed about the terms of postoperative care and examinations scheduled in 3 check points according to the scheme described below.

\section{Evaluation of the phonatory function}

The evaluation of the phonatory function was carried out using objective and subjective methods. The instrumental methods of voice assessment included the following:

- Laryngovideostroboscopy (LVS), in which the following parameters were examined: the quality of mucosal wave, regularity of vocal fold vibration, amplitude of vocal fold vibration, and the configuration of glottal closure. Each stroboscopic parameter was rated on a $0-2$ scale, where 0 - normal, 1 - limited dysfunction, 2 - severe dysfunction, e.g., absence of mucosal wave or inability of assessment.

- Measurement of the Maximum Phonation Time (MPT), which is an objective and noninvasive measurement of aerodynamic parameter of the phonatory function of the larynx. To measure MPT, the subject was 
asked to phonate a sustained /a:/ vowel at a comfortable pitch and loudness as long as possible during a single exhalation.

The subjective assessment of voice included:

- Voice Handicap Index (VHI) questionnaire - both its total value (VHI-T) and the values of each subscale, i.e., the functional state (VHI- F), physical state (VHI-P) and emotional state (VHI-E), were assessed. Total scores of VHI range from 0 to 120 , with 120 indicating the most severe vocal dysfunction.

- Voice-Related Quality of Life (V-RQOL) survey is a 10-point self-rating scale, which is more focused on the quality of life than on a handicap itself. A higher V-RQOL score points to a better V-ROOL reported by patients.

\section{Assessment of ventilatory function}

The ventilatory performance was assessed in an objective way using spirometry. The following respiratory parameters were taken into account: Forced Vital Capacity (FVC), Forced Expiratory Volume in the first second (FEV1), Maximum Expiratory Flow (MEF 25, 50, 75), Peak Expiratory Flow (PEF), Tiffeneau index (FEV1/FVC), and Forced Expiratory Flow (FEV 25, 50, 75). ${ }^{22}$

\section{Statistical analysis}

IBM SPSS Statistics v. 24 software (IBM Corp., Armonk, USA) was used to analyze the obtained results. All the parameters were statistically described and referred to the measures of central tendency and dispersion. Spearman's rank correlation coefficient (Spearman's rho) was used to identify a correlation among aggregated coefficients. Statistical significance of the treatment effects was verified with the Wilcoxon test. The value of $\mathrm{p}<0.05$ proved that there were significant differences in the data: p1 -before surgery compared to 1 month after the surgery, p6 - before compared to 6 months after the surgery, p 9 - before compared to 9 months after the surgery. The key results of the analytical process are presented in box-whisker plots.

\section{Results}

\section{Demographical data and clinical presentation}

The study included 31 subjects operated on in the Clinical Department of Otorhinolaryngology (Katowice, Poland). The final study group included 20 patients who completed a full cycle of post-surgery check-ups in 3 time check points: 1 , 6 and 9 months after the surgery. There were 16 women (80\%) and 4 men (20\%) in the study group. Mean age was 53.2 years. Depending on the clinical advancement of RE, the patients were divided into a group of $3^{\text {rd }}$ clinical advancement stage according to Bart ( 15 subjects) and $4^{\text {th }}$ clinical advancement stage (5 subjects). In subjects with RE stage 4, the main reason for reporting for surgery was dyspnea and in subjects with RE stage 3 (Fig. 1), the main symptoms were breathing disorders, hoarseness of voice and lowering of voice in women.

All the examined patients were active smokers. They were physical workers with no occupational vocal loading. The patients were qualified for mini-microflap surgery after preliminary examination including laryngological examination with LVS and assessment of phonatory and ventilatory function.

\section{Comparison of pre- and post-surgery assessment of the phonatory function}

Most of the results of the objective and subjective evaluation of the phonatory function indicated post-surgery improvement in comparison to the pre-surgery values. In the analysis of the results of LVS, which is the gold standard of imaging examinations of the function of the larynx, the improvement of the phonatory function was observed in the $6^{\text {th }}$ month after the surgery, with an increase in the trend lasting up until the $9^{\text {th }}$ month after the surgery. These results concerned all the assessed parameters in LVS: regularity of vocal fold vibration ( $\mathrm{p} 6<0.014$, $\mathrm{p} 9<0.001$ ), amplitude of vocal fold vibration ( $\mathrm{p} 6<0.004$, $\mathrm{p} 9<0.001$ ), the presence of mucosal wave (p6 $<0.001, \mathrm{p} 9<0.001)$, and the configuration of glottal closure (p6<0.003, p9 $<0.001)$.
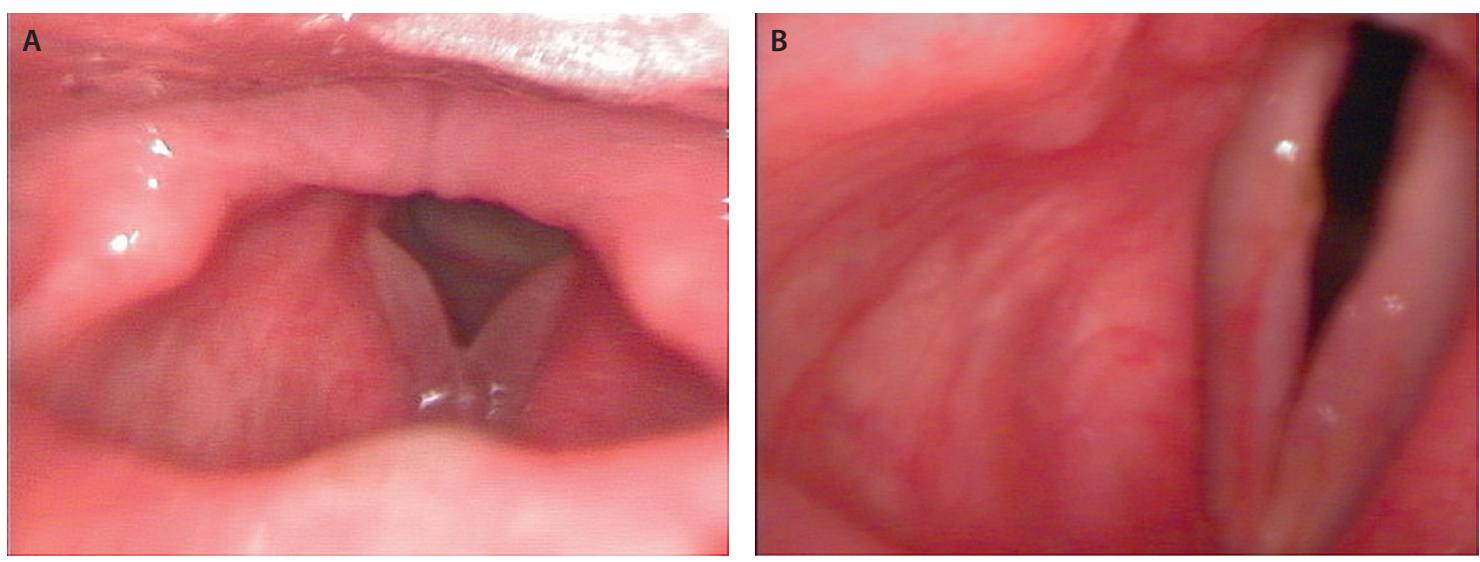

Fig. 1. Image

of larynx in laryngovideostroboscopy

of a patient with Reinke's edema stage 3 A - before surgery; B - 9 months after mini-microflap surgery 


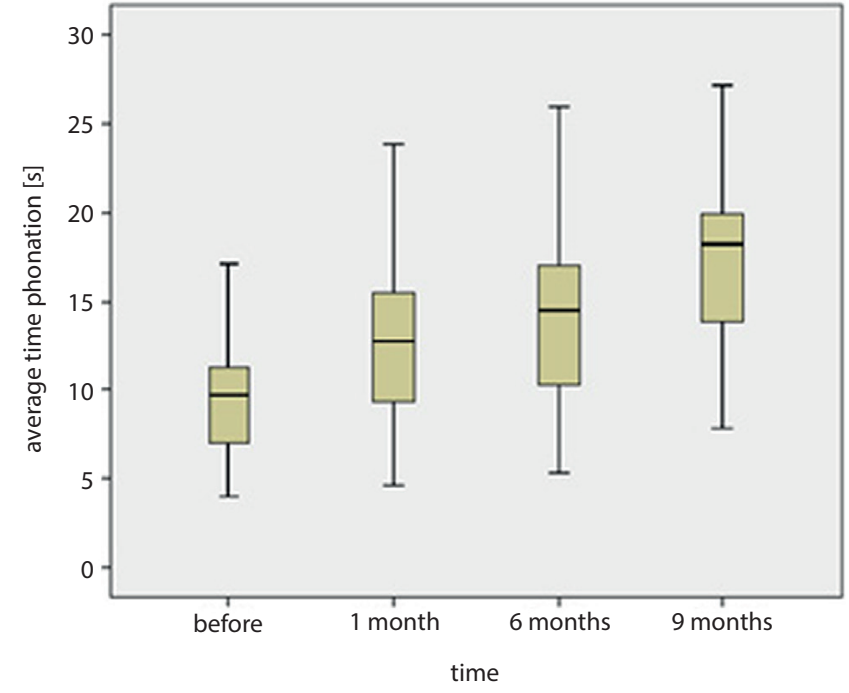

Fig. 2. The comparison of Maximum Phonation Time before and 1, 6 and 9 months after mini-microflap surgery

The study also indicated an improvement in the MPT, which is an objective aerodynamic indicator of the respiratory performance during phonation. Postsurgical increase in MPT was noticed in all patients. The research demonstrated a statistically significant improvement in the aerodynamic parameter (MPT) already 1 month after the surgery, with the rising trend persisting in the longterm observation. On average, there was an increase of $3.72 \mathrm{~s}$ during the 1-month observation after the surgery (p1 < 0.001), 4.79s in the 6-month observation (p6 < 0.001) and $7.88 \mathrm{~s}$ in the 9 -month observation (p9<0.001) (Fig. 2).

A self-assessment of the voice by means of VHI and V-RQOL revealed the post-surgery improvement of the voice from the patient's point of view. The total score of the Voice Handicap Index (VHI-T) dropped in all the patients, giving an average decrease of 26 points in 1 month ( $\mathrm{p} 1<0.001), 34$ points in 6 months ( $\mathrm{p} 6<0.001)$ and 47 points in 9 months ( $99<0.001)$ after the surgery (Fig. 3). Analogically, significant improvement concerned all the subscales of the VHI: physical - VHI-P, emotional - VHI-E and functional: - VHI-F, with p1 $<0.001$ significance. Improvement in V-ROOL scores was observed in 18 patients in 9 month, after the procedure. V-RQOL values increased moderately after the surgery by 8 (p1<0.001), 10 (p6 < 0.001) and 13 points (p9<0.001) in 1, 6 and 9 months, respectively (Fig. 4).

\section{Comparison of pre- and post-surgery assessment of the ventilatory function}

In the assessment of the ventilatory function, the most significant changes were noticed in the majority of patients after the surgery for the following parameters: Peak Expiratory Flow (PEF), Maximum Expiratory Flow (MEF 25\% and 75\%) and Forced Expiratory Flow (FEF 25\% and 75\%). The improvement in some ventilatory parameters was observed

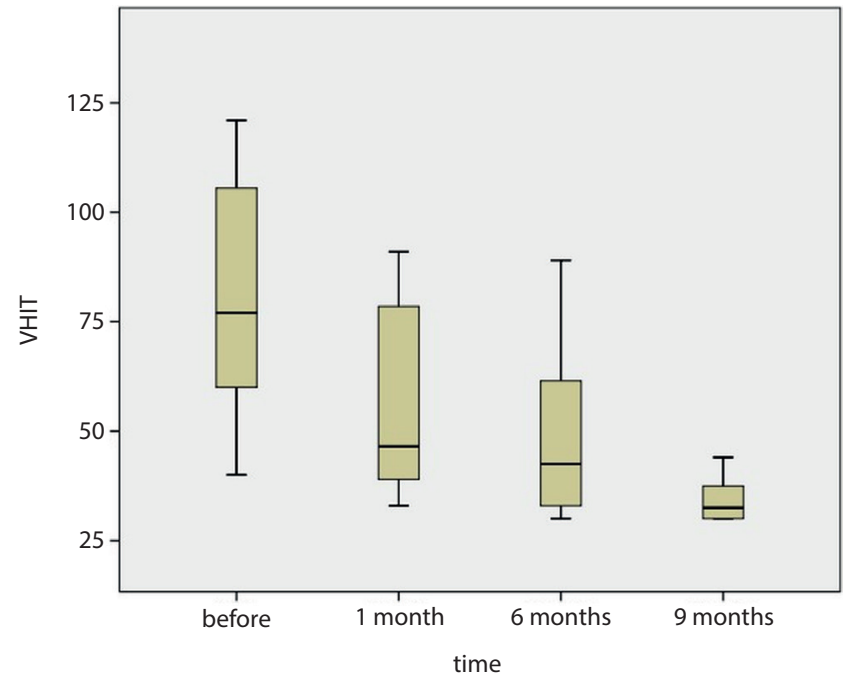

Fig. 3. The comparison of Voice Handicap Index Total before and after 1, 6 and 9 months after mini-microflap surgery

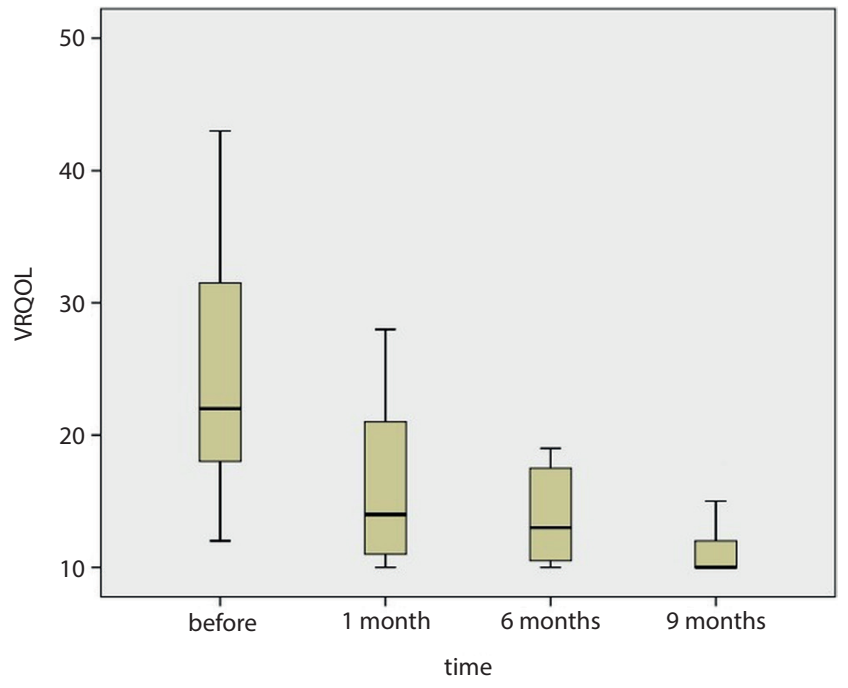

Fig. 4. The comparison of Voice-Related Quality of Life before and 1, 6 and 9 months after mini-microflap surgery

already 1 month after the surgery. The improvement concerned the following parameters: PEF $(\mathrm{p} 1=0.001)$, Forced Expiratory Volume in the first second (FEV1) (p1 = 0.024), Maximum Expiratory Flow MEF 25\% (p1 = 0.025) and MEF $75 \%(\mathrm{p} 1=0.002)$, and FEF $75 \%(\mathrm{p} 1=0.025)$.

In the assessment of the ventilatory function, a significant improvement was observed for most ventilatory parameters 9 months after the surgery: PEF ( $\mathrm{p} 9<0.001)$, FEV1 (p9 = 0.024), MEF 25\% (p9<0.001), MEF 75\% (p9<0.001), FEF 25\% (p9<0.001), and FEF75\% (p9<0.001). It should be underlined that the value of PEF parameter, which is described in literature as an important parameter monitoring the effectiveness of procedures widening the glottis, increased significantly already in the first month postsurgery. The increase persisted in 6 and 9 months postsurgery (p6 $<0.001$, p $9<0.001)$ (Fig. 5). 


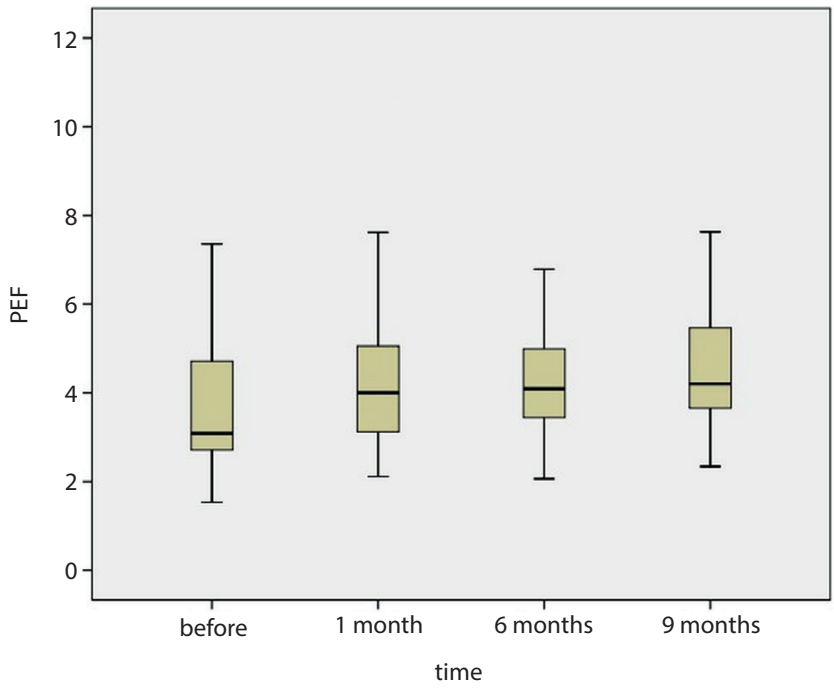

Fig. 5. The comparison of Peak Expiratory Flow before and after 1, 6 and 9 months after mini-microflap surgery

\section{Correlations between the parameters of phonatory and ventilatory function}

Analyzing the relation between the objective and subjective parameters assessing the phonatory function of larynx, the most significant correlation was observed 9 months after surgery for aerodynamic parameter MPT and Physical subscale of Voice Handicap Index (VHI-P): $\mathrm{r}=-0.449, \mathrm{p}=0.047$ (Fig. 6). Analogically, the study showed a correlation between MPT and V-ROOL 6 months after surgery $(\mathrm{r}=-0.511$, p $6<0.05)$ (Fig. 7). The longer MPT indicated that the patient experienced less difficulty in the physical aspect of voice projection. Analyzing the values of the phonation and ventilation indexes, we found the correlation between the MPT and PEF parameter in 1 month after the surgery, giving a statistically significant result of $\mathrm{p}=0.026$ (Fig. 8). The results indicate that conducting the mini-microflap technique in the $3^{\text {rd }}$ or $4^{\text {th }}$ stage of RE broadens the glottal area, increases MPT and decreases the PEF index, thus improving the respiratory efficiency of the glottis.

\section{Discussion}

An important aspect in the surgical management of BVFM, including RE, is the preservation of the surrounding normal tissue with as little disruption as possible; this is crucial to ensure optimal laryngeal functions postoperatively. It is advisable for surgeons operating on BVFM to use microsurgery techniques in order to prevent vocal fold damage and to preserve voice production. For this reason, the mini-microflap technique has become a more frequently used for the treatment of RE, as the functional structure of the vocal folds is maintained by preserving their epithelium intact, especially at the vibrating margin. ${ }^{23}$

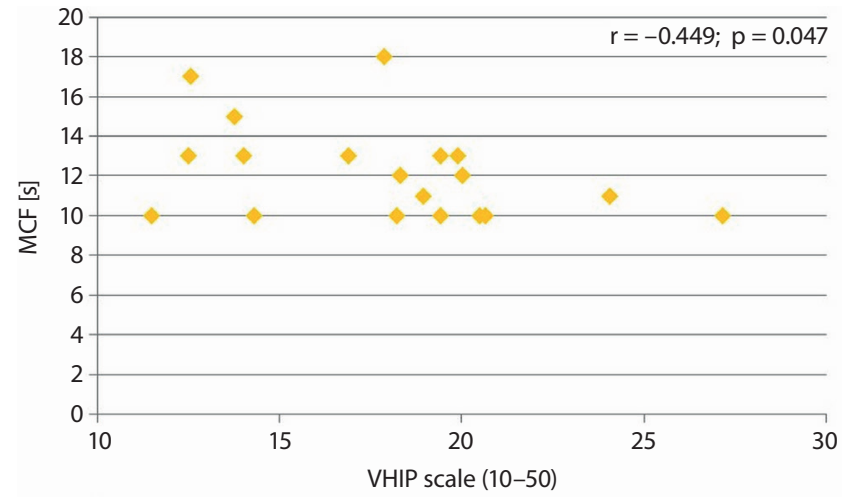

Fig. 6. Correlation between Maximum Phonation Time and Voice Handicap Index-P - physical scale

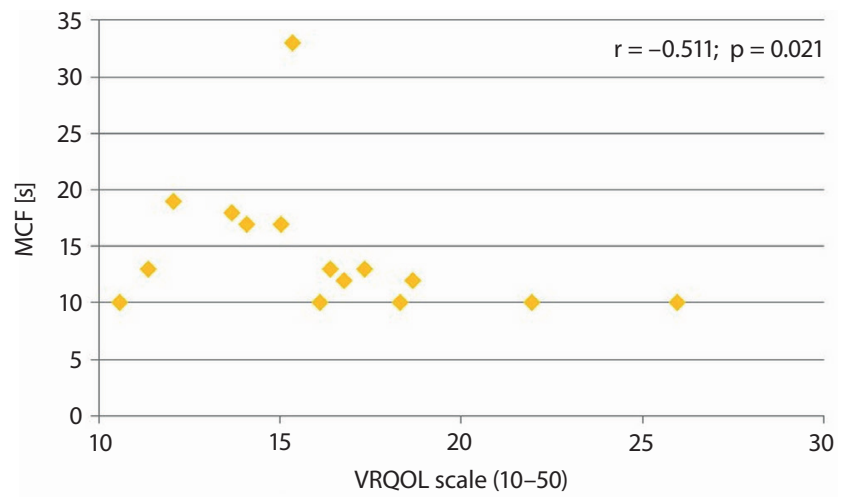

Fig. 7. Correlation between Maximum Phonation Time and Voice-Related Quality of Life

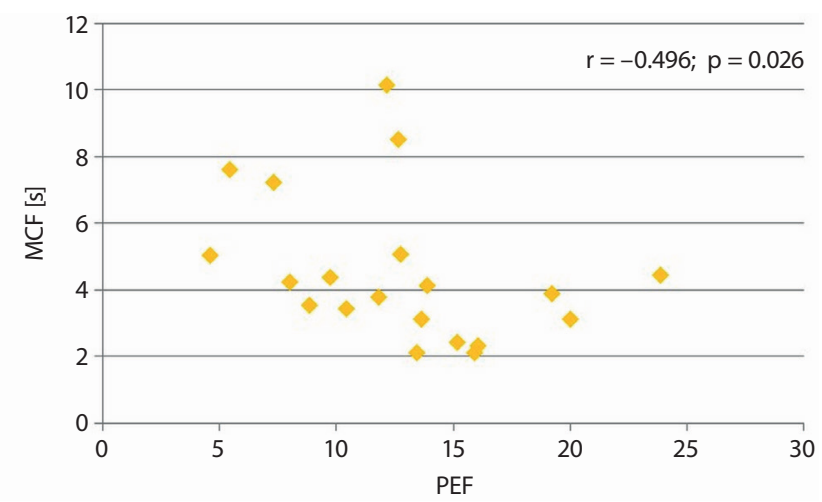

Fig. 8. Correlation between Maximum Phonation Time and Peak Expiratory Flow

The study presented the postoperative results in patients with advanced stages $\left(3^{\text {rd }}\right.$ and $\left.4^{\text {th }}\right)$ of RE who underwent mini-microflap surgery. Patients with obstructive RE suffer from deterioration in their overall quality of life due to progressive voice change and respiratory symptoms. ${ }^{24}$ Therefore, the examination involved a complex (objective and subjective) assessment of voice and spirometry, which were performed prior to surgery and 1, 6 and 9 months postoperatively.

The results of the study demonstrated postoperative improvement in both phonatory and ventilatory function. 
Our research indicates objective improvement of voice function evaluated by means the LVS examination, which still remains a gold standard in the diagnosis of laryngeal pathology. ${ }^{18,19}$ The significant improvement of LVS parameters was observed after 6 and 9 months after the surgery, particularly those indicating improvement of glottal closure (p6 $=0.003$, p $9<0.001$ ). These good long-term postsurgical results were also observed for the other assessed parameters in LVS, e.g., regularity of vocal fold vibration ( $66=0.014, \mathrm{p} 9<0.001$ ), and amplitude of vocal fold vibration (p6 $=0.004$, p9 $<0.001$ ). Furthermore, the research demonstrated a statistically significant improvement of the aerodynamic parameter (MPT) already 1 month after the surgery, with the rising trend persisting in the long-term observation $(\mathrm{p}<0.001)$. The study confirmed the results of Lim et al., who, in a study concerning 23 patients with RE treated by means of mini micro-flap technique, reported an improvement in MPT 2 months after surgery. ${ }^{24}$ These observations are of clinical value, given that considerable changes in the Reinke's area of the vocal fold affect the time of vocal fold vibration, shortening it, which in turn decreases the effectiveness of the expiration during phonation. Maximum Phonation Time, as an aerodynamic parameter, is an important element of the vocal function assessment, which indicates phonatory inefficiency of the larynx and respiratory-phonatory coordination disorder.

Given that recently an important role has been attached to the quality of life, the results of self-assessment of quality of voice were an important contribution to the study. The analysis of postsurgical results shows improvement of the VHI and V-ROOL in all time intervals $-1,6$ and 9 months after the mini-microflap surgery $(\mathrm{p}<0.001)$. These results are in line with the study concerning subjects with RE presented by Bassel et al. on the VHI-10 questionnaire 9 months after the surgery ${ }^{25}$ and Soner on the Voice Performance Questionnaire (VPQ) 6 months after the surgery. ${ }^{23}$ These observations, which are in accordance with our research, demonstrate that applying the mini micro-flap surgery technique in RE patients results in improvement of vibratory function of vocal folds, making them thinner and more suitable for vibratory maneuvers, which, in turn improves voice quality after the surgery.

In the assessment of ventilatory function, a significant improvement was observed for most ventilatory parameters 9 months after the surgery: PEF ( $\mathrm{p} 9<0.001)$, FEV1 (p9 = 0.024), MEF 25\% (p9<0.001), MEF 75\% (p9<0.001), FEF 25\% (p9 < 0.001), FEF 75\% (p9<0.001). It should be underlined that the value of PEF parameter, which is described in the literature as an important parameter monitoring the effectiveness of procedures widening the glottis, increased significantly already in the first month after the surgery. The increase persisted in 6 and 9 months after the surgery $(\mathrm{p} 6<0.001, \mathrm{p} 9<0.001)$. The results were in agreement with the studies of other authors, confirming the improvement of airflow stability and effectiveness of respiration after mini-microflap surgery. ${ }^{26-30}$

This research is the first Polish study showing a comparative analysis of the phonatory and ventilatory function after phonosurgery in patients with RE. A correlation between the MPT-aerodynamic phonatory parameter and the PEF parameter found 1 month after the procedure $(\mathrm{p}=0.026)$ may prove that reducing the mass of the vocal folds with mini-microflap surgery and widening of the glottis area improves the conditions of phonation.

Moreover, the satisfactory long-term post-surgery results of phonatory parameters assessed by means of LVS and voice self-assessment questionnaires revealed that the main goal of phonosurgery technique, i.e., maintaining the layered, functional composition of the vocal fold, was fulfilled.

It should be emphasized that our research has shown a postoperative improvement in the phonatory and ventilatory function of patients with RE, which persists for 9 months after the surgery for most of the examined parameters. The available literature on the subject presents the results of the mini-microflap surgery either 2 or 6 months after the surgery. ${ }^{23,24}$ Our study indicates that, in order to obtain adequate postoperative results after surgical intervention, it is crucial to provide long-term postoperative management, including vocal hygiene guidance. Therefore, the progress of the patient after phonosurgery must be monitored with a re-examination by means of subjective and objective methods not only in short-term (1 month), but also in long-term intervals (e.g., 6 and 9 months).

\section{Conclusions}

The study indicates that treatment with the mini-microflap technique in patients with advanced $R E$ ( $3^{\text {rd }}$ and $4^{\text {th }}$ stage) decreases the mass of the vocal folds and widens the glottis, thereby improving the aerodynamic conditions of phonation. Moreover, the study confirmed that the abovementioned microsurgery technique improves the quality of phonatory movements of the vocal folds, as it maintains their layered, functional structure. The applied instrumental and subjective methods of voice assessment enhanced the patients' overall well-being, including their V-ROOL.

\section{ORCID iDs}

Katarzyna Ura-Sabat (D) https://orcid.org/0000-0001-6825-5788 Joanna Morawska (1) https://orcid.org/0000-0002-9431-673X Wojciech Domka (1) https://orcid.org/0000-0003-4429-7638 Marta Gamrot-Wrzoł (D) https://orcid.org/0000-0003-0892-6935 Wojciech Scierski (D) https://orcid.org/0000-0003-3242-8047 Ewa Niebudek-Bogusz (D) https://orcid.org/0000-0002-5389-578X 


\section{References}

1. Rubin JS, Sataloff RT, Korovin GS. Diagnosis and Treatment of Voice Disorders. $4^{\text {th }}$ ed. San Diego, CA: Plural Publishing Inc; 2014:95-105.

2. Yonekawa H. A clinical study of Reinke's edema. Auris Nasus Larynx. 1988;15(1):57-58.

3. Tan $M$, Bryson $P$, Pitts $C$, Woo $P$, Benninger MP. Clinical grading of Reinke's edema. Laryngoscope. 2017 Oct:127(10):2310-2313.

4. Yonekawa H, Ohta F, Hirose H. Clinical classification of Reinke's edema. Folia Phoniat Logoped. 1992;44:92.

5. Siupsinskiene N, Skumaniene M. Phonatory characteristics following different endolaryngeal microsurgical techniques in Reinke's disease [in Lithuanian]. Medicina (Kaunas). 2002;38(10):982-989.

6. Kravos A, Hocevar-Boltezar I, Gersak K. Serum levels of sex hormones in males with Reinke's edema. Eur Arch Otorhinolayngol. 2013;270(1): 233-238.

7. Niemczyk K, ed. Otolaryngologia kliniczna. Warszawa, Poland: Medipage; 2015:1547-1549.

8. Szyfter W. Laryngologia. Poznań, Poland: Termedia; 2016:329-335.

9. Obrębowski A. Narzad głosu ijego znaczenie w komunikacji społecznej. Poznań, Poland: Wydawnictwo Naukowe Uniwersytetu Medycznego w Poznaniu; 2008:15-18.

10. Misiołek M, Niebudek-Bogusz E, Morawska J, Orecka B, Ścierski W, Lisowska G. Gender-related voice problems in transsexuals: Therapeutical demands. Endokrynol Pol. 2016;67(4):452-455.

11. Martins RH, do Amaral HA, Tavares EL, Martins MG, Gonçalves TM, Dias NH. Voice disorders: Etiology and diagnosis. J Voice. 2016;30(6): 761.e1-761.e9.

12. Colton RH, Casper JK, Leonard R. Understanding Voice Problem:APhysiological Perspective for Diagnosis and Treatment. $4^{\text {th }}$ ed. Philadelphia: Wolters Kluwer Health Adis (ESP); 2011:494.

13. Yonekawa $\mathrm{H}$, Nimii S, Hirose $\mathrm{H}$. A follow up study of Reinke's edema after surgery. In: Dejonckere PH, Peters HFM, eds. Communication and its Disorders: A Science in Progress. Proceedings of the $24^{\text {th }}$ Congress IALP Asterdam, 1998, Nijmegen, the Netherlands: Nijmegen University Press; 1999:375-377.

14. Dejonckere PH. Assessment of voice and respiratory function. In: Remacle M, Eckel H, eds. Surgery of Larynx and Trachea; $2^{\text {nd }}$ ed. Berlin, Germany: Springer-Verlag; 2009:11-26.

15. Tan NC, Pittore B, Puxeddu R. The ,'M" shadep microflap for treatment of complex Reinke's space edema of the vocal cords. Acta Otorhinolaryngol Ital. 2010;30(5):259-263.

16. Druck G, Mauri M. Use of the microdebrider for Reinke's edema surgery. Laryngoscope. 2000;110(12):2114-2116

17. Sommer C, Schults-Coulon HJ. Long-term results after microlaryngoscopic removal of Reinke's edema [in German]. HNO. 2007;55(5): 365-374.
18. Rzepakowska A, Sielska-BadurekE, Osuch-WojcikiewiczE, NiemczykK. Multiparametric assessment of voice quality and quality of life in patients undergoing microlaryngeal surgery: Correlation between subjective and objective methods. J Voice. 2018;32(2):257.e21-257.e30

19. Niebudek-Bogusz E, Kopczynski B, Strumillo P, Morawska J, Wiktorowicz J, Sliwinska-Kowalska M. Quantitative assessment of videolaryngostroboscopic images in patients with glottic pathologies. Logoped Phoniatr Vocol. 2017;42(2):73-83.

20. Caffier P, Schmidt B, Gross M, et al. A comparison of white light laryngostroboscopy versus autofluorescence endoscopy in the evaluation of vocal fold pathology. Laryngoscope. 2013;123(7):1729-1734.

21. Young VN, Mallur PS, Wong AW, et al. Analysis of potassium titanyl phosphate laser settings and voice outcomes in the treatment of Reinke's edema. Otol Rhinol Laryngol. 2015;124(3):216-220.

22. Miller MR, Hankinson J, Brusasco V, et al; ATS/ERS Task Force. Standardisation of spirometry. Eur Respir J. 2005;26(2):319-338.

23. Soner T, Melek KG, Ercan K, et al. The effect of surgical treatment on voice quality in Reinke's edema: An evaluation with vocal performance questionnaire and acoustic voice analysis. J Med Updates. 2013;3(2):56-61.

24. Lim JY, Choi JN, Kim KM, Choi HS. Voice analysis of patients with diverse types of Reinke's edema and clinical use of electroglottographic measurements. Acta Otolaryngol. 2006;126(1):62-69.

25. Bassel H, Olivier F, Teiga PS, Bouayed S, von Wihl S, Sandu K. Subjective voice assessment after endoscopic surgery for an obstructive Reinke edema using voice handicap index. Adv in Otolaryngol. 2015;2015:207085. doi:10.1155/2015/207085

26. Misiołek M, Namysłowski G, Warmuziński K, Ziora D, Czecior E. Efficacy of laser arytenoidectomy in bilateral vocal cord paralysis. The review of the contemporary surgical procedures. Chir Pol. 2003; (5) 2:91-96.

27. Orecka B, Misiołek H, Namysłowski G, et al. Functional results after the treatment of laryngeal stenosis [in Polish]. Otolaryngol Pol. 2007; 61(5):872-876.

28. Harnisch W, Brosch S, Schmidt M, Hagen R. Breathing and voice quality after surgical treatment for bilateral vocal cord paralysis. Arch Otolaryngol Head Neck Surg. 2008;134(3):278-284.

29. Swain SK, Sahu MC. Management of laryngeal airway in Reinke's edema: An anesthetic overview. Int JOtorhinolaryngol Clin. 2017;9(1): 35-37.

30. Salmen T, Ermakova T, Schindler A, et al. Efficacy of microsurgery in Reinke's edema evaluated by traditional voice assessment integrated with the Vocal Extent Measure (VEM). Acta Otorhinolaryngol Ital. 2018;38(3):194-203. 